\title{
Digital Muda - The New Form of Waste by Industry 4.0.
}

\author{
Jamila Alieva \\ Department of Industrial Economics, \\ Gavle University, Kungsbäcksvägen 47, 80176 Gävle, Sweden \\ Email: Jamila.Alieva@hig.se (Corresponding Author) \\ Robin von Haartman \\ Department of Industrial Economics, \\ Gavle University, Kungsbäcksvägen 47, 80176 Gävle, Sweden \\ Email: Robin.vonHaartman@ hig.se
}

\begin{abstract}
Lean management is an approach where value is created through the reduction of waste. Eight forms of waste were identified by the Toyota Company as worth considering while managing an efficient production process: overproduction, waiting, transport, over processing, inventory, movement, defects, and unused creativity. Modern manufacturing plants are being transformed by Industry 4.0, the fourth industrial revolution, which promotes a wide variety of technological solutions to increase innovativeness and competitive advantages. Technological solutions are created on the basis of data that must be analyzed to enable manufacturers to be more strategic in the decision-making process and generate new profit channels through data analytics. A conceptual framework was developed to investigate if the inefficient usage of data has a negative impact on manufacturing performance through the decision-making process. Semi-structured interviews were conducted in two leading manufacturing companies in Sweden that are following lean principles. A new form of waste, digital waste, was defined. This paper suggests considering digital waste as a new type of muda (waste), which is its theoretical contribution. From a practical perspective, the results of the paper encourage practitioners to pay extra attention to data analytics, work on the reduction of digital waste and establish new revenue channels based on data analysis.
\end{abstract}

Keywords: lean management, digitalization, digital waste, muda, data processing

\section{INTRODUCTION}

In 1990, the book The Machine that Changed the World revolutionized the perceptions of many scientists and practitioners about the manufacturing production process and the role of people in it. Soon, lean production became known worldwide, with the meanings of value and waste always at the center of attention. Waste (also known by Japanese word muda) was defined as an action in the production process that did not add value for the customer (Womack et al., 1990). In 2015, the fourth industrial revolution was proclaimed a movement affecting the manufacturing sector digitally. The academic community was concerned about the synergy of lean and Industry 4.0 and their compatibility (Kolberg and Zuhlke, 2015; Mrugalska and Wyrwicka, 2017).

Manufacturing companies have started investing in the technologies aligning the strategy with lean values (Sanders et al., 2017; Tortorella and Fettermann, 2017). Besides traditional product sales, companies offer after-sales services based on data analytics from the product or the production process. According to De Backer et al. (2017), the experience with 20 back-end factories in Asia shows that a combination of lean and Industry 4.0 techniques, can help manufacturers sustain improvement in labor costs and quality. Productivity was increased up to $50 \%$ for direct labor and up to $20 \%$ for maintenance productivity. The overall equipment effectiveness was increased up to $15 \%$, with an up to $50 \%$ decrease in customer complaints.

Manufacturing companies are offering more jobs for the specialist with a technical background, while engineers and operators are expected to adapt to the new digital environment (Bonekamp and Sure, 2015; Hecklau et al., 2016). Artificial intelligence (AI) is one of many examples where data analysis plays a major role. According to Tonby et al. (2019), Japan has the ambition to make AI development a strategic priority and recently announced new courses in its universities and technical schools to produce 250,000 graduates annually with proficiency in AI.

The importance of data in the manufacturing sector is growing. Factories are becoming smart and the tools are intelligent (Qin et al., 2016; Zhong et al., 2017). Many global manufacturers take previously isolated data sets, aggregate them, and analyze them to reveal important insights. By resetting different parameters, one chemical company was able to reduce its waste of raw materials by $20 \%$ and its energy costs by around $15 \%$, thereby improving overall value (Auschitzky et al., 2014). On the other hand, according to the chief technology officer of the Digital Manufacturing and Design Innovation Institute (King et al., 2015), "Manufacturing generates more data than. . . healthcare, more data than retail, finance. . . [Manufacturers] mostly throw away the data. Where they keep it, they don't know what to do." Advanced analytics provide a granular approach for manufacturers to analyze historical process data, identify patterns and relationships, and optimize the factors that 
prove to have the greatest effect on value and profit (Auschitzky et al., 2014).

Lean philosophy is aligned with manufacturing digitalization (Mrugalska and Wyrwicka, 2017; Rüttimann and Stöckli, 2016), but the meaning of waste has not received enough attention in the literature given the new circumstances of Industry 4.0. The concept of digital waste or digital muda has started appearing in scientific articles in different contexts. Corcoran (2012) mentions digital waste in the context of cloud computing with unnecessary data transport and network storage. Peoples and Hetherington (2016) raise the topic of digital legacy and the digital waste of people's data online after their deaths. Beliatis et al. (2018) discuss digital waste management in the context of LoRa networks and the Internet of Things. In a manufacturing context Romero et al. (2018), raise the topic of digital waste as a lost digital opportunity and wasted digital capabilities of the new digital manufacturing technologies. They define digital waste as any non-value adding digital activity to people, materials, machines, methods, and measurements in the digital lean enterprise (Romero et al., 2018). Authors also classify the waste as active or passive. However, Romero et al. (2018) focus their research on elimination of digital waste in cyberspace and lean automation, rather than focusing on why the waste from data can be classified as digital waste.

The purpose of the paper is to investigate if uncollected and unprocessed data can be considered as a new form of muda, or digital waste. The purpose is further specified in three research questions:

- Can partial or full ignorance of data collection at the manufacturing plant be considered a waste and/or leading to waste?

- Can data collected but not processed at the manufacturing plant be considered as a waste?

- Can data was processed with a specific purpose but did not lead to the expected result be considered a waste?

This study is limited to the discussion of data and digital waste. Other relations presented in the conceptual framework are not discussed in this study.

This paper aims to contribute to operations management literature with an extended definition of waste, digital waste, and its classification.

\section{LITERATURE REVIEW}

\subsection{Lean Manufacturing \& Waste}

The birthplace of lean production is the Toyota Company, which entered the Japanese motor vehicle industry in 1930 (Womack et al., 1990). By the late 1950s, lean production was a one of the phenomena leading to reduction in production costs. Small batches eliminated the carrying cost of big inventories (Slack et al., 2010). The parts were produced in small amounts, so they could be used directly at the assembly line to become a finished product (Womack et al., 1990). Consequently, lean production affected relations within the whole supply chain and the perception of consumers' demands (Slack et al., 2010; Womack et al., 1990).

Liker (2004) defines waste as anything that takes time but does not add value for customers. According to Slack et al. (2010), waste is anything other than the minimum amount of equipment, items, parts, and workers essential to production. According to Shah and Ward (2003), the waste consists of work-in-process inventory and unnecessary delays in flow time. In line with some other researchers (Liker, 2004; Shah and Ward, 2003; Slack et al., 2010), waste is defined in this paper as a process or action that does not add value for a customer while using equipment, production resources, or workers. Womack et al.'s (1990) philosophy of waste elimination consists of mapping all the activities and keeping only activities that add value while eliminating those that do not add any value. Elimination of waste is one of the most significant parts of the lean philosophy (Slack et al., 2010). There are eight types of waste in lean production: overproduction, waiting, transport, over-processing, inventory, movement, defects, and unused creativity (Liker, 2004; Oehmen and Rebentisch, 2010; Slack et al., 2010; Womack et al., 1990). Elimination of waste is a journey of learning to map the value-adding activities of production as well as the elimination of nonvalue-adding activities (Liker, 2004). Waste reduction techniques are used to improve the performance of the waste minimization program in manufacturing, combining the interests of lean manufacturing and green management (Fercoq et al., 2016).

Often manufacturing companies aim to be lean and green through lean management practices. To increase operational and environmental performance, manufacturers prioritize certain lean management practices for their strategic investments (Bai et al., 2019). Helleno et al. (2017) discuss the popularity of lean manufacturing and value stream mapping to develop manufacturing processes without waste in the production flow with a number of sustainability indicators. Jasti and Kodali (2016) discuss the barriers while implementing lean management: employee resistance, budget constraints, and lack of understanding of lean management principles on the shop floor. The drivers for the lean management implementation are customers' satisfaction and an organizational continuous improvement program (Jasti and Kodali, 2016).

\subsection{Industry 4.0 and $H R$}

Industry 4.0 influence human resource management through the continuous automation of different manufacturing processes (Hecklau et al., 2016). Manufacturing employees of the future will require a complex set of skills and a high level of education (Bonekamp and Sure, 2015; Richert et al., 2016; Schuh et al., 2015). Existing manufacturing specialists are required to shift their capacities to workspaces with advanced processes.

Job profiles in the manufacturing sector will become more complex and require continuous learning and training (Bonekamp and Sure, 2015; Hecklau et al., 2016). Training will ensure the adaptation of current manufacturing employees to the changing work environment. Technological support is going to become a guarantee for the manufacturing employees to realize their full potential in strategic decisions and to increase their flexibility in problem-solving (Gorecky et al., 2014). Industry 4.0 aims to support existing manufacturing jobs with new competencies and offer new jobs for the digitized generation in the manufacturing sector (Richert et al., 2016). 
Hecklau et al. (2016), developed a framework with a list of essential competencies (technical, personal, social, methodological) for manufacturing employees to work in a digital environment. Industry 4.0 is creating a new manufacturing environment where humans are expected to work in hybrid teams with smart robots (Richert et al., 2016). Schuh et al. (2015) discuss the Industry 4.0 environment as a new opportunity for work-based learning through a large amount of real-time data available during the production process. Their model was created to combine Industry 4.0 characteristics to support work-based learning (Schuh et al., 2015).

\subsection{Data Analysis}

Manufacturing companies are adopting digital technologies offered by Industry 4.0 (Mayr et al., 2018; Uriarte et al., 2018; Zhong et al., 2017). The big data environment plays a big role in the manufacturing sector. Collection of the raw data and analyzing these data leads to intelligent manufacturing based on discovered knowledge and intelligent decisions (Qin et al., 2016). Data processing is the most significant part of intelligent manufacturing, providing the right information for the right purpose at the right time (Zhong et al., 2017). Wagner et al. (2017) performed an analysis of the most positive impact of big data and analytics on continuous improvement, just-in-time manufacturing, standardization, takt time, and waste reduction. On the other hand, there are still many challenges with real-time data availability, decentralization of data acquisition, lack of motion data, and data security (Uriarte et al., 2018). Manufacturers with a big set of shop-floor data need to track and analyze hidden patterns of data, unknown correlations, market trends, and customer preferences to implement intelligent decisions (Zhong et al., 2017).

Rüttimann and Stöckli (2016) suggest that Industry 4.0 technologies need to be integrated into the lean framework, and Industry 4.0 needs to find the right domain of application to impact manufacturing performance. Current manufacturing requirements and the Industry 4.0 requirement can be merged and reached through the multilayered framework developed by Qin et al. (2016). The framework is based on 5C architecture, which has five levels: connection, conversion, cyber, cognition, and configuration. Wagner et al. (2017) developed a matrix that merges Industry 4.0 solutions (data acquisition and data processing, machine-to-machine communication, human-machine interaction) and elements of the lean production system. Data plays a key role in each level of the matrix, from information discovery to intelligent production. Uriarte et al. (2018) developed a conceptual framework where simulation increases the efficiency of lean processes and lean culture. Data simulation speeds up system improvements and supports the decision-making process with a positive effect on overall manufacturing performance.

The combination of lean manufacturing focusing on value-adding activities and boosting performance, as well as Industry 4.0 with a set of tools supporting the analysis of specific lean methods, is defined as lean 4.0 (Mayr et al., 2018). There are no defined achievement criteria, nor is there a roadmap of technologies for accomplishing Industry 4.0 (Qin et al., 2016). Lean 4.0 tools need to be selected carefully to achieve the specific process improvement, but not be considered a tool for cost reduction instead (Mayr et al., 2018). Zhong et al. (2017) discuss intelligent manufacturing in the context of Industry 4.0, where all the resources are converted into intelligent objects with an ability to sense, act, and behave. According to Uriarte et al. (2018), Industry 4.0 will automate the routine tasks performed by workers, which will allow them to become decision makers and flexible problem solvers in a growing intelligent manufacturing production. According to Mayr et al. (2018), data usability, selective provision of information, acceptance of users, profitability, and ethics are the key success factors in integration of Industry 4.0 technologies on the shop floor.

\subsection{Conceptual Framework}

The conceptual framework (Figure 1) was developed to identify new relationships that are leading toward the broader interpretation of muda, such as including digital waste.

\subsubsection{Performance}

Cost and quality of the product and process is dependent on manufacturing performance (Fercoq et al., 2016; Liker, 2004; Oehmen and Rebentisch, 2010; Slack et al., 2010). Reduction of waste leads to reduction in costs of the product and process (Slack et al., 2010; Womack et al., 1990). Performance improvement is dependent on goals or a set of decisions defined by management (Slack et al., 2010).

\subsubsection{Decision}

The literature describes the rapidly growing importance of data in the manufacturing industry, which supports the decision-making process through intelligent analysis and analytics (Mayr et al., 2018; Qin et al., 2016; Rüttimann and Stöckli, 2016; Uriarte et al., 2018; Wagner et al., 2017; Zhong et al., 2017). Human factors play a big part in data analysis and the decision-making process. One of the newly discussed topics is the importance of human factors in lean manufacturing under the influence of Industry 4.0 (Bonekamp and Sure, 2015; Gorecky et al., 2014; Hecklau et al., 2016; Richert et al., 2016; Schuh et al., 2015). The set of skills and requirements for the manufacturing employee has evolved from those of ordinary machine operators to data analysts and cybersecurity managers.

\subsubsection{Data}

Data plays a crucial role in the manufacturing industry. Intelligent collection, analysis, and interpretation of data are value-adding activities leading to successful decisions, with a positive impact on manufacturing performance (Qin et al., 2016; Zhong et al., 2017).

\subsubsection{Muda}

Despite the increasing importance of data collection and analysis, there has been no research done to investigate if uncollected, unprocessed, or misinterpreted data should be considered as muda in manufacturing. 


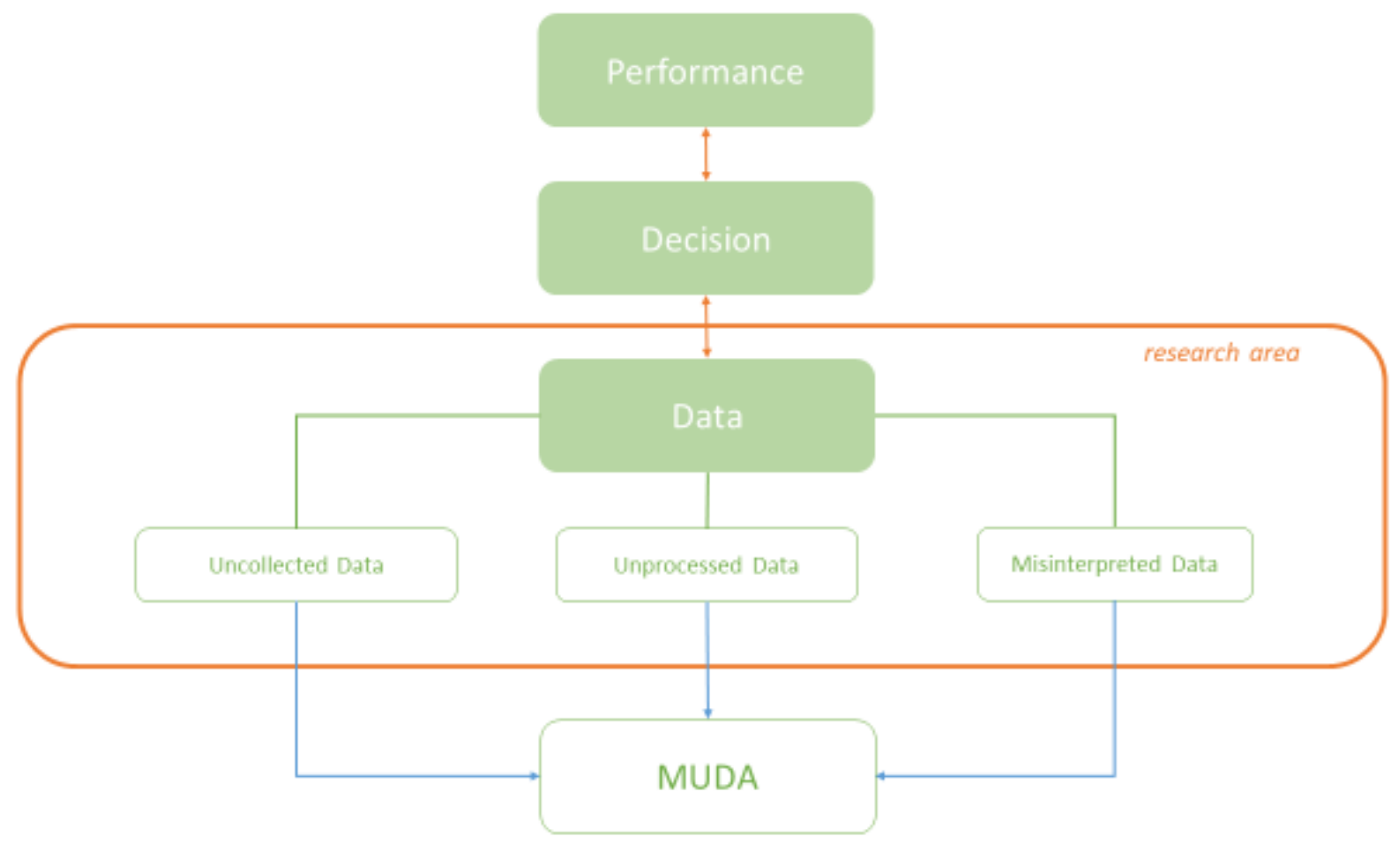

Figure 1 Conceptual framework

\section{METHOD}

This study aims to investigate the phenomenon of new forms of waste. The framework proposed by the authors includes a set of variables and patterns. The research questions of the study investigate why digital waste should be considered as muda. For studying a phenomenon in its natural setting and contributing to the development of new theory responding to the research questions about the digital waste, case study research is the most applicable method (Voss et al., 2002). The research is exploratory, with a company as the unit of analysis (Barratt et al., 2011). To avoid being subjective with results from one company, our research is comparative and involves two manufacturing companies to permit investigating any contrast in the results. The two selected companies have many similarities, such as the lean management approach, number of employees, industry, organizational culture, and dates of establishment. The companies are world market leaders in several specific spheres, which limited the option to increase the number of cases to more than two (Stuart et al., 2002).

Semi-structured interviews were an approach of the study to collect the data and not limit responders by the boundaries of the question, to gain broader knowledge about the phenomenon (Barratt et al., 2011). Voss et al. (2016) suggest obtaining reliability through the use of a case protocol and develop a case study database to enable repeating the study operations. The case study protocol was developed prior to the data collection. Interview questions are available in the appendixes, in the hope that researchers may repeat the study following the same scenario. According to Voss et al. (2016), construct validity can be obtained through the establishment of multiple sources of evidence. In this study, interviews were used as a primary source of evidence. Social media, such as companies' LinkedIn profiles and YouTube channels were used as a secondary source of evidence in data collection and analysis. According to Voss et al. (2016), external validity supports understanding of the study results and the ability to generalize those results beyond the immediate case study. For external validity, a multi-case study was conducted.

The seven semi-structured interviews contained interview questions based on theory and aligned with the conceptual framework. Questions were addressed to the specialists from two world-leading manufacturing companies. Interview candidates were chosen and contacted through the LinkedIn professional network, based on their job titles, job descriptions, and working experience. The difference in organizational structures of the two companies limited our ability to find identical specialists with similar job titles and job descriptions. Interview candidates were structured in three divisions, responding to the questions based on their qualification and experience in strategy, production and human resources (Table 1). The interviews were coded, with the data processed through conventional content analysis (Elo and Kyngas, 2008; Hsieh and Shannon, 2005).

\section{RESULTS}

\subsection{Company $A$}

Company $\mathrm{A}$ is a European manufacturing company with a focus on industrial equipment, founded around 150 years ago. The company employs over 30000 employees in more than 20 countries. Company A has sales offices in 180 countries as well as customer centers in half of those countries. About $40 \%$ of the company's revenue is generated from after-sales services. Company A espouses lean values and has a group of qualified specialists focused on lean production and lean management. 
Table 1 Summary of the interviews

\begin{tabular}{cccccc}
\hline DIVISION & & & CONTACT & TIME & METHOD \\
\hline \multirow{2}{*}{ STRATEGY } & 1 & COMPANY A & Head of Production Digital Transformation & 1 hour & face-to-face interview \\
\cline { 2 - 7 } & 2 & COMPANY A & Head of Digital Machining & 1 hour & face-to-face interview \\
\cline { 2 - 7 } & 3 & COMPANY B & IT Strategy \& Innovation Manager & 2 hours & face-to-face interview \\
\hline \multirow{2}{*}{ PRODUCTION } & 4 & COMPANY A & Business Process Expert Manufacturing Execution & 30 minutes & phone interview \\
\cline { 2 - 7 } & 5 & COMPANY B & Plant Manager & 30 minutes & phone interview \\
\hline \multirow{2}{*}{ HUMAN RESOURCES } & 6 & COMPANY A & Manager for Recruitment & 1 hour & phone interview \\
\cline { 2 - 7 } & 7 & COMPANY B & HR Manager & phone interview \\
\hline
\end{tabular}

\subsubsection{Waste (muda)}

Company A confirms the existence of eight types of waste; overproduction and movement are the types they most commonly see. To predict and prevent waste, the company organizes daily improvement meetings, works on lead-time reduction, collects data from multiple sources, and processes the data to information. Company A anticipates potential challenges related to waste and plans to prevent them through the digitalization of processes, such as replacement of paper-based documents on the shop floor with tablets, where the tasks and reports would be kept in a digital format and integrated with its enterprise resource planning (ERP) system. Company A has observed a direct impact of waste on the company's performance. The goal of production management is a reduction of waste to keep the costs low with the help of digitalization. According to the management, "digitalization is a journey," and Company A has already started.

\subsubsection{Data}

Company A confesses that they lack a consistent approach to data collection. Some data comes from the production process, while other data is generated by smart tools. Production units work independently of each other. Some of them are more successful than others in data collection and data processing in a systematic way. A big amount of data is stored in order to evaluate any need, request, or complaint of the customer. Historical data is also one of the main sources to improve the quality and reduce the cost of any product. All the data analysis is motivated by some purpose. Company A is mostly motivated to analyze the data for sustainability and competition purposes. Data analysis is a resource-consuming process requiring a bridge between the product consumers, data operators, and data scientists. It is necessary to set a goal for data analysis, which needs to derive from the practical problem.

\subsubsection{Decision}

Company A is in need of specialists with technical skills, as its LinkedIn profile announced. Recruiters offer jobs to data scientists, since data collection and data processing have become priority activities in the reduction of waste of time and overproduction. Selection of data for analysis and reaching the results is time-consuming for Company A, with big production processes. It takes up to two years for a manufacturing IT specialist to get familiar with historical data and process it to valuable information. There is of practice in outsourcing employees with analytical skills, because data transparency is a sensitive issue. On the other hand, communication skills and psychological profile are the barriers managers name to finding the technical background specialists to work in teams and collaborate with professionals from different divisions. To ascertain whether a decision based on data analysis has a positive or negative impact on performance is a time-consuming process. Technical jobs require long-term evaluation, sometimes up to 10 years.

\subsubsection{Performance}

Time and value are variables for Company A to measure its performance. Investment in digital technologies will yield good outcomes, once the manufacturing employees adjust to the changes. Data analysis aims for longterm prediction based on trial and error and efforts including a failure scenario. Forecasting based on unsuccessful analysis should not be considered just a failure. It is also a part of the learning curve that creates big value for the company.

\subsection{Company $B$}

Company B is a European manufacturing company with a focus on engineering, founded around 160 years ago. The company employs over 40000 employees in more than 160 countries. Company B is one of the internationally recognized role models in Industry 4.0, investing extensively in $\mathrm{R} \& \mathrm{D}$ and collaborating with leading research universities around the world. Company B spouses lean values and is developing long-term relationships with its customers based on lean values.

\subsubsection{Waste (muda)}

Company B analyzes problems at the shop floor. One of the biggest challenges causing a waste of time is the utilization of machines and keeping the data from the machines in different locations. To predict and prevent waste, managers examine the definition of waste on each shop floor instead of generalizing it. To improve the process of waste tracking, managers are aiming for the single storage of data from multiple sources, where it can be converted into good quality information. Optimization of data storage and data processing are the key priorities in the reduction of waste. To overcome the possible challenges with process optimization, Company $\mathrm{B}$ is relying on an improved leadership strategy and cultural changes with a deeper understanding of the meaning of waste. To improve performance management, they prioritize visualization of data from all the sources; improved utilization of machines based on data, and active digitalization of production processes. 


\subsubsection{Data}

Company B has a complex infrastructure working in different business areas with a number of divisions in each area, where each division has its own factories. Company B is collecting two types of data: production data and product data. The maturity of data from all the sources has very different levels. Some data is integrated with the customer relationship management (CRM) system and suppliers' systems. Company B has numerous motivations to analyze the data and process it to information. A lot of the analysis is dynamic and happening with real-time data. The motivation for data analysis derives from production, customers, market needs, and business needs. There have been some failures in data collection, with a poor understanding of what quality data is. To prevent failure in data collection, management concentrates on practical production problems to define the priorities in data collection that could impact their solution. Data analysis has a high potential to impact the company's performance through decisions based on a bottom-up approach.

\subsubsection{Decision}

Company B reacts to the growing importance of data in several ways. Recruiters search for technical specialists with analytical skills to join the teams of manufacturing workers. At the same time, engineers with plenty of work experience are offered training to learn and adapt to the new digital changes in production divisions. Company B has internship programs in collaboration with leading technical universities to attract entry-level employees and avoid the existing competence gap. Outsourcing specialists with technical background for the advanced data analysis could be an option if not for the challenge of data transparency and corporate restrictions. In the future, it is planned to have mixed teams with in-house and outsourced technical specialists.

\subsubsection{Performance}

Company B considers time and customer feedback as key variables to measure performance. Flexibility with opportunities to make mistakes is a big boost for innovation and creativity, which are important in the working process on analytics teams. Moreover, current manufacturing customers purchase a product with a service contract, which extends their relations with manufacturers and offers unlimited opportunities for product improvement. Analysis of data is mainly the source for learning within the organization as well as an opportunity to make sharper decisions.

\section{DISCUSSION}

In this paper, waste is defined as a process or action that does not add value for customers by using equipment, production resources and workers. The discussion section will analyze whether data collection, data processing, and data analysis can be considered a waste.

\subsection{Data Collection}

Company A stores the production data to reflect the needs, requests and complains of the customers. An example of Company A end product is equipment that is sold to other manufacturers and plays a part in the production of other products. The equipment is smart and generates data that Company A has access to. The equipment, for example might fail to reach its capacity during the production process, cause defects, or consume unexpected amounts of energy. When the problem is detected, the client returns to Company A to get help. If Company A cannot collect the data about their finished goods (equipment), there is no possibility to spot the problem and find the reason for its solution (create value). How company $\mathrm{A}$ is producing the end product is another source of data. It is important to settle on what machines are to be used, what time is to be spent, what employees are involved and which raw materials are used to produce a particular product. If Company's A customer complains about the equipment and the evidence is supported with a product data analysis, an internal investigation will be required to detect a reason for the problem. Production data simplifies the investigation process and offers facts that can lead to possible solutions. The result is either detecting the problem and stating it, or detecting no problem, proving that with data, and redirecting the problem to another level. The collection of production data is a source of defect detection and possible prevention.

An example of Company B's end product is tools that are sold for other manufacturers to use in their production process. These tools are smart and generate data. If the end product does not reach the expected quality, it is important to investigate the reason for failure. Perhaps that manufacturing employees do not use the tools efficiently, or the material used in combination with tools causes a defect to the tool. The data generated and collected from the tool can provide a good basis for the problem investigation and solution. To produce tools for customers, Company B uses their own smart tools. The tools generate data sent to the wireless network on the shop floor. Collected data about the tools allows knowing how efficiently each set of tools is used, in which area of the shop floor and for what reasons. Collected data about the production process, in this example utilization of smart tools, is a source of reduction of waste in time, waste in motion and waste in resources (tools).

Analysis of theory and cases lead to an assumption that equipment and items became smart, collecting and producing the data. Workers use the data to implement their jobs efficiently and eliminate the eight well-known types of waste. Thus, data has become an essential part of production. Partial or full ignorance of data collection at the manufacturing plant is a barrier for a product's good quality potential and can possibly be considered a waste when focusing on product quality. There is so far no confirmation of whether uncollected data is a barrier for faster operation or the potential for lower cost service.

\subsection{Data Processing}

Company A doesn't have a consistent method to collect data from multiple sources. Consequently, it is a challenge to process the data from all the available sources to reliable information, develop meaningful conclusions, and achieve value. Collected product or production data is not always processed. Lack of an urgent need, lack of time, and lack of resources are the main reasons for not processing the collected data until it becomes an urgent task. For example, new/potential customers of Company A could be interested in purchasing a Company A product, in this example 
equipment. A potential customer will request facts and statistics proving that Company's A product can handle high workload for a long time and has a low rate of defects. This information is possible to provide only when the product data (from other clients) is processed and available upon request. Processed data can increase competitive advantage and lead to solid strategic decisions and higher customer satisfaction.

Company B separates data collection into two types: product data and process data. Products have different levels of complexity, so the maturity of data collected is different and cannot be processed the same way or easily integrated with other systems such as ERP or CRM. Company B is working on the development of the central unit of data processing with an understanding of what value it will create for the company. Sometimes defects can be recognized only over time, when the final product will reach the end user. For example, if a vehicle produced by the customer of Company $\mathrm{B}$ has a defect and is dangerous for use, it would be necessary to investigate if other vehicles produced at the same time are acceptable for use, who is responsible for the mistake, and how to prevent it. Detection of defects might affect the whole supply chain, including Company B. It is a time-consuming process influencing the public image of all the participants. Company B can prevent possible conflicts related to their reputation and prevent possible defects by processing product/production data and detecting possible deviations in advance.

Analysis of theory and cases from the two manufacturing companies leads to the conclusion that data collection takes time, but does not create value if the data is not processed. Consequently, unprocessed data can be considered a waste.

\subsection{Data Analysis}

Company A is dependent on data analysts, who measure the performance of the work be over time. The analysis is associated with a defined purpose. Trial and error is a natural process of the analysis, which Company A does not consider as a failure but rather perceives as a learning process. Company A collects and processes the data of their customers. The final goal is to meet the customers' requests, for example to increase the sustainability potential of the product by decreasing the energy consumption. Historical data about the product is a main source of finding the way to reach a new goal. The approach requires time, innovative thinking, and the skills of highly qualified employees. It is never clear enough what data needs to be selected for the analyses to meet the goal. Several scenarios can be considered before the goal is reached. In a positive case, one of the scenarios will lead to success. Continuously improving the product and reducing the waste in energy consumption on the customer's side create the value for both the customer and Company A.

Company $\mathrm{B}$ is investing resources in developing a new generation of in-house specialists through the internship program to uplift the data analysis to a competitive level. Customer feedback and flexibility in responding to mistakes boost innovations. On one hand, data processed with a specific purpose that does not lead to the expected results should be considered a waste, since those activities cannot add direct value. On the other hand, the indirect impact is great and is the basis for the final results that do create a value-adding activity. Company B producing a set of traditional tools. However, every new set of tools is defined as an advanced generation of tools. Tools are becoming smarter and more electronic. The potential for new abilities of tools is discovered through the analysis of previous capabilities. Data analysis of the product and its behavior during the production process (tool utilization) is fundamental for continuous improvement. Analysis leads to the interpretation of data and actions, such as new (advanced) tool development. When the new tool is significantly better then the previous generation tool and the analysis is based on historical data, the conclusion is that data interpretation created the value.

If unsuccessful data analysis is a learning process and value-adding activity, then it is not a waste. But if unsuccessful data analysis cannot be mapped as a valueadding activity/process, it is a waste. There is no clear conclusion whether data processed with a specific purpose that did not lead to the expected results should be considered a waste. The question needs further investigation.

Table $\mathbf{2}$ is a summary of examples of product and production data in the two companies.

\section{CONCLUSIONS}

The two studied companies focused on both product and service sales, so from a long-term perspective, the service package tends to play an equal or even dominant role in the performance of manufacturers. Collecting, processing, and interpreting data into information is a value-adding activity/process of lean production. There are two types of data that can potentially be a reason for waste: data about the product and data about the production process.

Three levels of digital waste were identified during the production process. The first level of digital waste is partial or full ignorance of data collection either about the product or its production. The second level is when data is collected but not transformed into the information that creates value and improves process efficiency. The third level is when data is collected and analyzed, but the analysis does not lead to any improvements. The reason for this could be unimportant data collection or poorly chosen priorities for analysis. However, interviewed practitioners are not positive about an advanced level of digital waste, perceiving it as a learning curve.

The main contribution of the study is an identification of a new form of waste, digital waste, which can come from either the product or the production process. Digital waste complements classic knowledge about production waste (Liker, 2004; Slack et al., 2010; Womack et al., 1990) under the influence of Industry 4.0. The study also contributes to the research of Zhong et al. (2017), discussing the importance of intelligent manufacturing in the context of Industry 4.0. The study contributes to Romero et al. (2018) by joining the discussion of a definition of digital waste.

The practical contribution of the research is a confirmation of a new form of waste that can influence the cost management of manufacturing products, encourage transparency for collaboration on a digital level, and enhance investments in technologies and technical specialists to provide analytical services along with manufacturing products. 
The study is limited by investigating only large manufacturing companies. We recommend that the framework proposed be validated by small and medium enterprises with advanced digital technologies. The study was also limited by looking at data from production and products only. We suggest that other data flows through the supply chain be validated in the framework, such as ERP systems, digital documents, and so forth. The study aimed to investigate why the inefficient usage of data from the production process can be classified as digital waste and how this waste can have an impact on performance throughout the decision-making process. For future studies, we suggest investigating how digital waste is impacting performance in a more specific context, such as cost, flexibility, or management efficiency.

Table 2 Data examples

UNCOLLECTED DATA

UNPROCESSED DATA

MISINTERPRETED DATA

- The equipment is smart and generates data.

- The equipment might fail to reach its capacity during the production process, cause defects, or consume an unexpected amount of energy.

PRODUCT - If data is not collected, there is no possibility to spot the problem and find the reason for its solution.

- In contrast, uncollected product data leads to wasted time and creates a barrier in the continuous improvement process.

COMPANY A

• It is important to decide which
machines to use, how much time to spend, which employees will be involved and which raw materials to use for producing a particular product.

- Production data simplifies the investigation process and offers facts PRODUCTION that can lead to possible problem solutions.

- The collection of production data is a source of defect detection and possible prevention.

- In contrast, uncollected production data leads to waste in time and creates a barrier in the continuous improvement process.
- Collected (product/production) data is not always processed.

- Lack of urgent need, lack of time, and lack of resources are the main reasons for not processing the collected data until it becomes an urgent task.

- Processed data can increase competitive advantage.

- Processed data leads to solid strategic decisions, and higher customer satisfaction.

- In contrast, unprocessed data leads to wasted time and unused creativity. Unprocessed data is also a barrier to continuous improvement.
- The final goal is to meet the customer's request with data analysis.

- Several scenarios are considered before the goal is reached.

- Only one of the scenarios will lead to success.

- It will create value for both the customer and the company.

- In contrast, other scenarios of data analysis that did not lead to success did not create value. Data analysis that did not create value and misinterpreted the data for the specific solution resulted in waste.
- Tools are smart and generating data.

- The production process is dependent on tools.

- The data generated and collected from the tool can give a good basis for the problem investigation and solution.

PRODUCT - In contrast, uncollected product data
leads to waste in time and creates a barrier in the continuous improvement process.

COMPANY B

- Tools generate data and connect to the wireless network.

- Collected data about the production process is a source of reduction of

PRODUCTION waste in time, motion, and resources.

- In contrast, uncollected production data leads to wasted motion, waste in time, and creates a barrier in the continuous improvement process.
- Detection of defects affects the whole supply chain.

-A time-consuming process influencing a public image.

- Processed data prevents reputation conflicts.

- Processed data prevents defects.

- Detection of deviations occurs in advance.

- In contrast, unprocessed data leads to waste such as rework and waiting. Unprocessed data is a barrier to continuous improvement.
- Data analysis of the product and its behavior during the production process is fundamental for continuous improvement.

- Analysis leading to the interpretation of data and actions, such as new (advanced) product development.

- Analysis based on historical data create the value.

- In contrast, other scenarios of data analysis that did not lead to success did not create value. Data analysis that did not create value and misinterpreted the data for the specific solution resulted in waste. 


\section{REFERENCES}

Auschitzky, E., Hammer, M. and Rajagopaul, A. (2014, July). How big data can improve manufacturing. Retrieved from https://www.mckinsey.com/business-

functions/operations/our-insights/how-big-data-canimprove-manufacturing.

Bai, C., Satir, A. and Sarkis, J. (2019). Investing in lean manufacturing practices: An environmental and operational perspective. International Journal of Production Research, 57 (4), pp. 1037-1051.

Barratt, M., Choi, T.Y. and Li, M. (2011). Qualitative case studies in operations management: Trends, research outcomes, and future research implications. Journal of Operations Management 29, pp. 329-342.

Beliatis, M.J., Mansour, H., Nagy, S., Aagaard, A. and Presser, M. (2018). Digital waste management using LoRa network: A business case from lab to fab. Global Internet of Things Summit in Bilbao.

Bonekamp, L. and Sure, M. (2015). Consequences of Industry 4.0 on human labour and work organization. Journal of Business and Media Psychology 6 (1), pp. 33-40.

Corcoran, P.M. (2012). Cloud Computing and Consumer Electronics: A Perfect Match or a Hidden Storm?, IEEE Consumer Electronics Magazine, 1 (2), pp. 14-19.

De Backer, K., Mancini, M. and Sharma, A. (2017, February). Optimizing back-end semiconductor manufacturing through Industry 4.0 . Retrieved from https://www.mckinsey.com/industries/semiconductors/ourinsights/optimizing-back-end-semiconductormanufacturing-through-industry-40.

Elo S. and Kyngas H. (2008). The qualitative content analysis process. Journal of Advanced Nursing 62 (1), pp. 107-115.

Fercoq, A., Lamouri, S. and Carbone, V. (2016). Lean/green integration focused on waste reduction techniques. Journal of Cleaner Production 137, pp. 567-578.

Gorecky, D., Schmitt, M., Loskyll, M. and Zuhlke, D. (2014). Human machine interaction in the Industry 4.0 era, Twelfth IEEE International Conference on Industrial Informatics (INDIN), Porto Alegre, Brazil, pp. 289-294.

Hecklau, F., Galeitzke, M., Flaschs, S. and Kohl, H. (2016). Holistic approach for human resource management in Industry 4.0, 6th CLF - 6th CIRP Conference on Learning Factories, Gjøvik, Norway, pp. 1-6.

Helleno, A. L., Isaias de Moraes, A.J. and Simon, A.T. (2017). Integrating sustainability indicators and lean manufacturing to assess manufacturing processes: Application case studies in Brazilian industry. Journal of Cleaner Production 153, pp. 405-416

Hsieh, H. F., and Shannon, S. E. (2005). Three approaches to qualitative content analysis. Qualitative Health Research 15 (9), pp. 1277-1288.

Jasti, N.V.K. and Kodali, R. (2016). An empirical study for implementation of lean principles in Indian manufacturing industry. Benchmarking: An International Journal, 23(1), pp. 183-207.

King, B., Rassey, L. and Salvo. J. (2015, October). Interviewed by Richard Kelly for McKinsey: The digital-manufacturing revolution: How it could unfold. Retrieved from https://www.mckinsey.com/business-

functions/operations/our-insights/the-digital-manufacturingrevolution-how-it-could-unfold.

Kolberg, D. and Zuhlke, D. (2015). Lean automation enabled by Industry 4.0 technologies, IFAC online, 48 (3), pp. 18701875.

Liker, J. K. (2004). The heart of the Toyota Production System: Eliminating waste, in The Toyota Way: 14 Management Principles from the World's Greatest Manufacturer, McGraw-Hill, New York.

Mayr, A., Weigelt, M., Kuhl, A., Grimm, S., Erll, A., Potzel, M. and Franke, J. (2018). Lean 4.0. A conceptual conjunction of lean management and Industry 4.0. Procedia CIRP 72, pp. 622-628.

Mrugalska, B. and Wyrwicka M.K. (2017). Towards lean production in Industry 4.0. Procedia Engineering 182, pp. 466-473.

Oehmen, J., and Rebentisch, E. (2010). Waste in Lean Product Development. LAI Paper Series "Lean Product Development for Practitioners, Lean Advancement Initiative (LAI), Massachusetts Institute of Technology, Cambridge, MA.

Peoples, C. and Hetherington, M. (2015). The cloud afterlife: Managing your digital legacy, IEEE International Symposium on Technology and Society, ISTAS 2015, Dublin, pp. 1-7.

Qin, J., Liu, Y. and Grosvenor, R. (2016). A Categorical Framework of Manufacturing for Industry 4.0 and beyond. Procedia CIRP 52, pp. 173-178.

Richert, A., Shehadeh, M., Plumanns, L., Groß, K., Schuster, K. and Jeschke, S. (2016). Educating engineers for Industry 4.0: Virtual Worlds and Human-Robot-Teams, Empirical Studies towards a new educational age, 2016 IEEE Global Engineering Education Conference (EDUCON), Abu Dhabi, UAE, pp. 142-149.

Romero, D., Gaiardelli, P., Powell, D., Wuest, T. and Thrurer, M. (2018). Digital lean cyber-physical production systems: The emergence of digital lean manufacturing and the significance of digital waste, IFIP Advances in Information and Communication Technology 535, pp. 11-20.

Rüttimann, B. G. and Stöckli, M. T. (2016). Lean and Industry 4.0-Twins, partners, or contenders? A due Clarification Regarding the Supposed Clash of Two Production Systems. Journal of Service Science and Management 9 (6), pp. 485500

Sanders, A., Elangeswaran, C. and Wulfsberg, J. P. (2016). Industry 4.0 implies lean manufacturing: Research activities in Industry 4.0 function as enablers for lean manufacturing. Journal of Industrial Engineering and Management 9 (3), pp. 811-833.

Shah, R., and Ward, P. T. (2003). Lean manufacturing: Context, Practice Bundles, and Performance. Journal of Operations Management 21 (2), pp. 129-149.

Schuh, G., Gartzen, T., Rodenhauser, T. and Marks, A. (2015). Promoting work-based learning through Industry 4.0, The Fifth Conference on Learning Factories 2015, Bochum, Germany, pp. 82-87.

Slack, N., Chambers, S. and Johnston, R. (2010). Lean operations and JIT, in R. D. Reid and N. R. Sanders (eds.), Operations Management, 5th edition, Pearson Education, Harlow, UK.

Stuart, I., McCutcheon, D., Handfield, R., McLachlin, R. and Samson, D. (2002). Effective case research in operations management: A process perspective. Journal of Operations Management 20, pp. 419-433.

Tonby, O., Woetzel, J., Choi, W., Seong, J. and Wang, P. (2019, July). Asia's future is now. Retrieved from https://www.mckinsey.com/featured-insights/asiapacific/asias-future-is-now.

Tortorella, G. L. and Fettermann, D. (2017). Implementation of Industry 4.0 and lean production in Brazilian manufacturing companies. International Journal of Production Research 7543, pp. 1-13.

Uriarte, A. G., Ng, A. H. and Moris, M. U. (2018). Supporting the lean journey with simulation and optimization in the context of Industry 4.0. Procedia Manufacturing 25, pp. 586-593.

Voss, C., Tsikriktsis, N., and Frohlich, M. (2002). Case research in operations management. International Journal of Operations \& Production Management 22 (2), pp. 195-219.

Wagner, T., Herrmann, C. and Thiede, S. (2017). Industry 4.0 impacts on lean production systems. Procedia CIRP 63, pp. 125-131.

Womack, J. P., Jones, D. T. and Roos, D. (1990). The rise of lean 
production, in The Machine that Changed the World, Macmillan, New York.

Zhong, R. Y., Xu, X., Klotz, E. and Newman, S. T. (2017).
Intelligent Manufacturing in the Context of Industry 4.0: A review. Engineering 3 (5), pp. 616-630.

Jamila Alieva is a Ph.D. candidate in the Faculty of Engineering and the Environment, Department of Industrial Management at the Gavle University. She holds a Bachelor of Science in the Business Computing Science from the University of Westminster, Tashkent Uzbekistan and Master of Science in Strategic Project Management from Heriot-Watt University, Edinburgh UK. Her research focuses on lean management, manufacturing management, digital technologies, and industry 4.0.

Robin von Haartman is an Associate Professor (Docent) at the University of Gävle, where he researches and teaches supply chain management and related subjects. He received his PhD from KTH Royal Institute of Technology. His research currently covers issues such as green logistics and manufacturing strategy. The results of previous studies have been published in journals such as International Journal of Operations and Production Management, International Journal of Logistics: Research and Applications and Journal of Purchasing and Supply Management. 